\title{
Enkele voorbeelde van die wisselwerking tussen samestellers en gebruikers van vakwoordeboeke
}

\author{
W. van Z. de Villiers \\ Departement Stralingstegnologie, Atoomenergiekorporasie, Posbus 582, Pretoria, 0001
}

Meningsverskille tussen leksikograwe en taalgebruikers kan maklik voorkom. Die volksmond steur hom dikwels nie aan reëls nie; trouens, dit is soms baie moeilik om die spreektaal in netjiese kompartemente te plaas. Ook binne die vaktaal kan verskille tussen die voorkeure of voorskrifte van vakterminoloë en die terme wat deur algemene gebruik ingeburger word, nie altyd vermy word nie. Wat egter saak maak, is hoe hierdie potensiële konflik deur albei partye hanteer word. Hopelik word daar gedurig, soos in hedendaagse onderhandelingsituasies, na wen-wen-oplossings gesoek.

Die samesteller van 'n vakwoordeboek het die moeilike taak om te orden en so ver as moontlik reëls neer te lê, maar nogtans 'n gebruikersvriendelike produk te verskaf. Soortgelyk het die terminologiegebruiker die verantwoordelikheid om konsekwentheid en wetenskaplike korrektheid in die gebruik van vaktaal na te streef. Die beste manier waarop wetenskaplikes kan verseker dat terminologie saam met die vak groei, is om aktief aan die proses van die skepping, beoordeling en normering van nuwe terme deel te neem. Saam daarmee moet gewaak word teen die ondeurdagte saamdra van ongewenste terme wat weens veranderde behoeftes nie meer aanvaarbaar of akkuraat genoeg is nie, of teen die ondeurdagte gebruik van terme wat weens spesialisering in 'n bepaalde vakgebied subtiel van betekenis verander het.

Die mening van prof. Johan Combrink' dat die beste Afrikaans dié is wat in gegewe omstandighede die eerste keer vir 100 persent kommunikasie sorg, kan net so op vaktaal van toepassing gemaak word. Al beveel die Internasionale Unie vir Suiwer en Toegepaste Chemie ("IUPAC") die sistematiese benaming etanoësuur aan, sal die chemikus beswaarlik kan klaarkom sonder om die triviaalnaam asynsuur te gebruik. Daar is talle voorbeelde waar'n bepaalde term in 'n spesifieke nywerheidsektor gebruik word, meestal ter wille van doeltreffender kommunikasie, maar 'n ander term (vir dieselfde begrip of produk) in ' $n$ ander bedryf of in wetenskaplike geskrifte. Selfs die land van herkoms van die spreker of skrywer kan soms uit sy keuse van woorde of terme afgelei word. Hierdie en ander aspekte wat deur samestellers van vakwoordeboeke in ag geneem moet word, is deur Scheffer ${ }^{2}$ bespreek.

Wat wel belangrik is, is dat die terminologiegebruiker gedurig van hierdie praktyke, en die gevare daaraan verbonde, bewus sal wees. Dit beteken dat hy/sy in 'n nuwe situasie of omgewing, of tydens kontak met kundiges uit ander vakgebiede, moet seker maak dat daar nie misverstande kan ontstaan weens taalgebruik wat eie aan sy/haar werkskring is maar vir die ander spreker moontlik 'n ander betekenis kan hê nie. By die gebruik van vakwoordeboeke moet die leser hom/haar ook vergewis van die leksikografiese hantering van trefwoorde en hul vertaalekwivalente, met ander woorde wat met verskillende tipes woordeboek- inskrywings bedoel word.

In 'n vorige artikel ${ }^{3}$ is verwys na enkele gevalle waar verskille voorkom tussen terme wat op grond van wetenskaplike en taalkundige beginsels deur vakterminoloë aanbeveel word en dié wat in die omgang gebruik word. Verdere voorbeelde uit die chemie en fisika sal vervolgens bespreek word. Dit sal hopelik bydra tot die vind van 'n middeweg waar die leksikograaf wel die wense van die taalgemeenskap binne perke sal akkommodeer, terwyl die terminologiegebruiker sal probeer om akkuraat, ondubbelsinnig en op konsekwente wyse te kommunikeer.

\section{1. molekulêre teenoor molekuul-}

In die Nuwe Chemiewoordeboek ${ }^{4}$ (NCWB) word die onderskeid getref dat atomêr of atomies as vertaling van atomic gebruik word vir verwysing na iets "in atoomvorm", terwyl atoom- gebruik word wanneer "van of deur atome" ter sprake is. Dit word dan ook algemeen so gebruik, byvoorbeeld atomêre waterstof of atomiese waterstof, maar atoomabsorpsie en atoommassa.

Op soortgelyke wyse behoort molecular dan met molekuul- vertaal te word vir die begrip "van of deur molekule" en met molekulêre vir "in molekuulvorm". Die verboè vorm het egter al, reg of verkeerd, om historiese redes algemene inslag gevind. Die feit dat genoemde onderskeid nie in Engels getref word nie, het waarskynlik daartoe bygedra. Wetenskaplikes praat algemeen van molekulêre massa, - struktuur, - orbitaal en - sif. Terblanche ${ }^{5}$ vertaal molecular deurgaans met molekulêr. Die $N C W B$ en die Kernbedryfwoordeboek ${ }^{6}$ gee egter in sommige (maar nie dieselfde) gevalle albei Afrikaanse skryfwyses aan, waarskynlik om bestaande gebruike te akkommodeer.

Dit is nogtans vreemd dat, waar' $n$ meelsif en molekuulsif albei verhoed dat onderskeidelik meelkorrels en molekule van bepaalde groottes deurgelaat word, ons die een 'n molekulêre sif noem. Molekuulsif en ander soortgelyke terme sal sekerlik wetenskaplik meer korrek wees.

\section{Vertaling van surface area}

In wetenskaplike taal word onderskei tussen

surface : oppervlak (die boonste deel) en area : oppervlakte, area ('n afmeting).

Die term surface area is al op verskeie maniere vertaal, bv. oppervlakte van oppervlak(!), ${ }^{5}$ oppervlakte 4 en oppervlakarea ${ }^{5,6}$ Hoewel laasgenoemde vir die leek koddig mag klink, is dit die ingeburgerde term. Dit is so in die hersiene Fisikawoordeboek opgeneem, en die inskrywing van oppervlakte in die NCWB behoort ook so verander te word. 


\section{Vertaling van surface tension}

Die bestaande Fisikawoordeboek en die $N C W B$ gee oppervlakspankrag as Afrikaans vir surface tension. In die omgangstaal word oppervlakspanning egter algemeen gebruik, soos dit trouens ook in Terblanche en die Kernbedryfwoordeboek verskyn. Die hersiene Fisikawoordeboek gee dit ook so, ${ }^{8}$ met die verklaring "krag per eenheid lengte in die oppervlak van 'n vloeistof". Dit word ook onderskei van surface stress : spanning in die oppervlak (krag per eenheid oppervlakte).

\section{4. uitloog en elueer}

Die werkwoord leach word gewoonlik as uitloog g $^{4,5}$ of $\operatorname{loog}^{6}$ vertaal. Vir elute, soos in kolomchromatografie gebruik, word elueer, uitwas of deurwas aanbeveel. Die middel waarmee eluering gedoen word, is dan

eluant : elueermiddel, eluant, uitwasmiddel, deurwasmiddel

en die vloeistof wat tydens eluering versamel word, is

eluate : eluaat, uitwasstof, deurwasstof.

Hoewel afleidings van elueer meestal in kolomchromatografie gebruik word, is daar chemici wat uitloog, uitloogkromme, ens. verkies. Behalwe dat iets soos uitloogsel dan vir eluaat gebruik sal moet word om konsekwentheid te behou, kan dit verwarring by 'n toehoorder of leser uit die mynbedryf skep, waar (uit)loging vir spesifieke prosesse gebruik word wat heeltemal van chromatografiese eluering verskil. Aangesien in die vakterminologie so ver as moontlik probeer word om een term vir een begrip te gebruik, is dit dus wenslik dat elueer as Afrikaans vir elute gebruik sal word, met uitloog gereserveer vir leach.

\section{5. akkuraatheid en presisie}

Sommige chemici het teen die volgende inskrywing in die Nuwe Chemiewoordeboek beswaar gemaak:

$$
\begin{aligned}
\text { akkuraatheid (noukeurigheid) : } & \text { 1. accuracy; } \\
& \text { 2. closeness (e.g.of fit); } \\
& \text { 3. precision. }
\end{aligned}
$$

Die beswaar hierteen (heeltemal tereg) is dat daar, veral in analitiese chemie, 'n duidelike verskil tussen akkuraatheid en presisie (as Afrikaans vir precision) is. Eersgenoemde verwys na die mate van ooreenstemming tussen 'n gemete waarde en die "korrekte" een (byvoorbeeld die aanvaarde waarde vir 'n bepaalde komponent van 'n verwysingsmateriaal). ${ }^{9}$ Presisie word egter gebruik vir die ooreenstemming tussen onafhanklike toetsresultate wat onder voorgeskrewe kondisies verkry is.

Uit 'n leksikografiese oogpunt is dit belangrik dat daar ook na die omgekeerde inskrywings gekyk word, naamlik

accuracy : akkuraatheid, noukeurigheid

closeness : akkuraatheid, noukeurigheid (bv. van passing)

precision : 1. akkuraatheid, noukeurigheid

\section{2. presisie}

Daar behoort geen beswaar teen die gebruik van akkuraatheid en noukeurigheid as sinonieme te wees nie. Die inskrywing vir precision verskil egter van dié vir accuracy deurdat dit op twee verskillende betekenisse of gebruiksvelde dui. Die eerste een geld byvoorbeeld vir die vertaling van "the operation was performed with great precision" met "die operasie is met groot noukeurigheid uitgevoer". Presisie, daarenteen, is van toepassing op bogenoemde voorbeeld uit analitiese chemie. Net so beteken dit dus dat die inskrywings teenoor akkuraatheid in die Afrikaanse deel van die NCWB nie as sinonieme bedoel is nie, maar verskillende betekenisse aan die doeltaalkant aandui.

\section{Bedanking}

Die skrywer bedank graag verskeie kollegas, asook dr. D.F. Louw, mev. C. Marais (Nasionale Terminologiediens) en mnr. T. McLachlan (Staatstaaldiens) vir hul hulp en insette.

\section{LITERATUURVERWYSINGS}

1. Combrink, J. (1996). Afrikaans is dit alles: van loslit- tot hoftaal, Beeld, 6 Mei.

2. Scheffer, C.J. (1986). Enkele oorwegings by die saamstel van 'n vakwoordeboek, S.Afr. Tydskr. Natuurwet. en Tegnol., 5, 161.

3. De Villiers, W. van Z. (1996). Nuwe terme in chemie en verwante gebiede, S.Afr. Tydskr. Natuurwer. en Tegnol., 15, 35.

4. Louw, D.F. (Red.) (1991). Die Nuwe Chemiewoordeboek (Staatsdrukker, Pretoria).

5. Terblanche, H.J. (1976). Engels-Afrikaanse Tegniese Woordeboek (Nasou, Kaapstad).

6. Taalkommissie van die Atoomenergiekorporasie (1990). Kernbedryfwoordeboek (Atoomenergiekorporasie, Pretoria).

7. Vaktaalburo van die SA Akademie vir Wetenskap en Kuns (1977). Fisikawoordeboek (Butterworths, Durban).

8. Louw, D.F. (1996). Persoonlike kommunikasie.

9. International Organization for Standardization (1992). Terms and definitions used in connection with reference materials, ISO Guide 30, Second Edition, Switzerland. 


\title{
Die skryfwyse van samestellings met selfstandige naamwoorde
}

\author{
W. van Z. de Villiers \\ Departement Stralingstegnologie, Atoomenergiekorporasie, Posbus 582, Pretoria, 0001 \\ P.L. Crouse \\ Departement Prosestegnologie, Atoomenergiekorporasie
}

Ten spyte van dekades se harde werk deur taalkundiges en onderwysers om Afrikaanssprekendes in die beginsels van los en vas skryf te onderrig, word nog steeds heelwat probleme in hierdie verband ondervind, soos gereeld in reklamestukke, verslae en ander dokumente gesien word. Dit is selfs nog meer ontstellend dat skryfwysefoute so dikwels voorkom in dokumente wat opgestel word deur spesialiste in die natuurwetenskappe - mense wat hulle juis toelê op die soeke na orde en die gebruik van sodanige orde en reëls tot voordeel van die mensdom.

Die meeste probleme in geskrewe vakkommunikasie kom voor by die skryf van samestellings met 'n selfstandige naamwoord as kernkomponent (naamwoordelike samestellings). Dit is te verstane aangesien die meeste vakterme naamwoorde is. Een van die oorsake vir skryfwysefoute is waarskynlik dat baie skrywers steun op die vae reël "een begrip, een woord". Daar word dikwels nie gelet op betekenisaspekte soos die onderlinge verband tussen die opeenvolgende woorddele wat saam 'n konsep benoem nie. Aspekte van woordbou soos die verbuigings-e by byvoeglike naamwoorde en verbindingsletters by selfstandige naamwoorde bly dikwels ook in die slag. Kennis van beginsels wat geld by los en vas skryf sou daartoe kon bydra dat skryfwyses soos die volgende vir die taalgebruiker gemotiveerd is, en nie bloot arbitrêr nie:

\author{
vaste stof (Eng.: solid) \\ vloeistof (Eng.: liquid) \\ vloeibare stikstof (Eng.: liquid nitrogen) \\ vloeibarestikstoftemperatuur (Eng.: liquid nitrogen tem- \\ perature) \\ statiese magneetveld (Eng.: static magnetic field) \\ onsekerheidsbeginsel (Eng.: uncertainty principle)
}

Hoewel daar 'n groot aantal komplekse reëls vir die los en vas skryf van woorde is, en daar ook heelwat uitsonderings bestaan, kan 'n aantal vereenvoudigde reëls geformuleer word wat die meeste skryfwysefoute met betrekking tot naamwoordelike samestellings in natuurwetenskaplike kommunikasie kan uitskakel.

1. Indien 'n selfstandige naamwoord die kern van 'n bepaalde begrip vorm, en direk bepaal word deur een of meer voorafgaande selfstandige naamwoorde of 'n werkwoord, móét die onderskeie dele vas geskryf word, bv.:

selfstandige naamwoord(e) + selfstandige naamwoord oksidasiereaksie, temperatuurmeting, distillasiekolom, chloorverbinding, elektronaffiniteit, kalsiumsulfaat, kernkragsentrale, silwerbromiedkolloied, atoommassaeenheid (die koppelteken word hier gebruik weens die vokaalopeenhoping) werkwoord + selfstandige naamwoord

moniteertoestel, draaimoment, vloeistof, vriespunt, vervaltempo, kookpunt, oksideermiddel

Let wel, 'n samestelling met meer as twee dele wat tot verskillende woordsoorte behoor, kan bv. gevorm word deur ' $n$ reeds bestaande samestelling as bepaler te gebruik by ' $n$ nuwe naamwoordelike kern, bv. kookpuntkromme (kookpunt + kromme) en vloeistoffase (vloeistof + fase).

2. In teenstelling met bogenoemde geld die volgende primêre reël met betrekking tot byvoeglike naamwoorde steeds: Indien 'n selfstandige naamwoord voorafgegaan word deur 'n byvoeglike naamwoord (verbuig of onverbuig), word dié twee meestal los geskryf, bv. suiwer stof, sterk basis, vloeibare stikstof, eksperimentele parameters, binêre legering, kovalente binding.

Daar is egter wel 'n aantal gevalle waar die byvoeglike naamwoord vas aan die selfstandige naamwoord geskryf word, bv. in witgoud, suurlemoen, droëvrugte, Nuwejaar. Dit is gewoonlik die gevolg van betekenisverdigting, of omdat die vasskryfkombinasie ' $n$ ander betekenis as die losskryfkombinasie het. In laasgenoemde geval het die betekenis van die b.nw. nie noodwendig verander nie, maar eerder die kombinasie s'n (vergelyk byvoorbeeld suur lemoen en suurlemoen, asook wit papier en witskrif). Verder val die hoofklem in 'n samestelling soos witgoud op die eerste lid, terwyl albei lede in 'n woordgroep soos suiwer stof redelik sterk beklemtoon word. Uitspraaktempo speel dikwels ook 'n rol.

3. Indien 'n naamwoord voorafgegaan word deur 'n byvoeglike naamwoord én 'n ander selfstandige naamwoord, moet bepaal word op watter selfstandige naamwoord die byvoeglike naamwoord betrekking het.

Indien die b.nw. op die eerste naamwoord betrekking het, móét al drie woorde vas geskryf word, bv. vinnigeneutronbestraling, langtermynmetings, laminêrevloeikabinet, hoëfrekwensiesein. Los geskryf sou vinnige neutronbestraling vertolk kon word as "neutronbestraling wat teen hoë spoed uitgevoer word", en laminêre vloeikabinet sou weer geïnterpreteer kon word as “'n vloeikabinet wat laminêr is". Soortgelyk mag die oningeligte leser dalk oor die hoogte van 'n hoë frekwensiesein wonder! (Die genoemde samestellings val dus in dieselfde klas as bekendes soos suurlemoensap en warmwaterbottel.)

Indien die b.nw. egter op die tweede naamwoord of die samestelling as geheel betrekking het, word die twee naamwoorde vas geskryf, maar staan los van die byvoeglike naamwoord, bv. molêre uitdowingskoëffisiënt, statiese magneetveld (d.w.s. 'n tipe magneetveld), vry padlengte (sê iets van die padlengte). 
4. As een of meer verbindingsletters aan die eerste deel van 'n samestelling geheg word, kan dit nooit los van die daaropvolgende deel geskryf word nie. Ons skryf dus altyd onsekerheidsbeginsel, skeidingselement en koningswater, maar nooit *onsekerheids beginsel, *skeidings element en *konings water nie. Ander bekende voorbeelde is waenhuis, boereplaas, kinderkamer.

5. Waar die dele van 'n saamgestelde selfstandige naamwoord (spesifiek 'n samestelling met twee naamwoordelike dele) deur die tussenplasing van 'n verboë byvoeglike naamwoord van mekaar geskei word, word 'n afstandskoppelteken gebruik, of die samestelling word as drie aparte woorde geskryf:

rekord-jaarlikse omset of rekord jaarlikse omset langtermyn-antimikrobiese terapie of langtermyn antimikrobiese terapie

Waar verbindingsletters gebruik word, is die afstandskoppelteken verpligtend, bv. stads-elektriese ingenieur.

6. Samestellings met 'n eienaam- plus soortnaamelement kan volgens die Afrikaanse woordelys en spelreëls op vyf verskillende maniere geskryf word:

Van de Graaffiersneller, Van de Graaff-versneller, Van de Graaff-Versneller, Van de Graaff versneller, Van de Graaff Versneller

Mohrtitrasie, Mohr-titrasie, Mohr-Titrasie, Mohr titrasie, Mohr Titrasie

In gevalle waar die oorspronklike eienaamgedeelte nie meer as sodanig gebruik word nie en dit algemeen sonder die hoofletter geskryf word, is die eerste van die genoemde vyf skryfwyses verkieslik, soos in bunsenbrander en dieselenjin.

Let wel, by reëls 5 en 6 word die keuse van 'n skryfwyse aan die gebruiker oorgelaat, waarna dit uiteraard konsekwent in 'n bepaalde dokument gebruik moet word.

7. By samestellings met 'n afkorting, simbool of syfer as eerste lid word 'n koppelteken tussen die betrokke lid en die res van die samestelling gebruik, bv. DNS-molekuul, M.Sc.-graad, $100 \mathrm{~W}$-gloeilamp, $5{ }^{\circ} \mathrm{C}$-styging. Wanneer 'n b.nw. afgekort word, word dit egter los van die s.nw. geskryf, bv. NG Kerk, SA Lugdiens.
Indien bostaande skryfbeginsels na die oordeel van die skrywer lompheid meebring, is daar wel maniere om dit te oorkom. Dit kan byvoorbeeld gedoen word deur omskrywing, veral in die geval van lang samestellings of dié wat nie algemeen gebruik word nie, bv. bestraling met vinnige neutrone in plaas van vinnigeneutronbestraling. Net so is regulasies m.b.t. elektriese masjinerie sekerlik meer elegant as elektriesemasjinerieregulasies! Indien dit wenslik is om dieselfde volgorde in die samestelling te behou, byvoorbeeld in navolging van ' $n$ algemeen gebruikte term in 'n ander taal, kan koppeltekens (met sorg) gebruik word. Die genoemde voorbeelde sou dus as vinnigeneutron-bestralings, langtermyn-metings en elektriesemasjinerie-regulasies geskryf kon word. Hier is dit belangrik dat die koppelteken tussen die hoofkomponente van die samestelling geplaas word, eerstens om betekenisgroepering te behou en tweedens omdat so 'n koppelteken nooit tussen die verboe b.nw. en die eerste s.nw.-komponent van sulke samestellings geplaas word nie. Vinnige-neutronbestralings sal dus nie korrek wees nie.

Spelling en skryfwyse behoort nie as blote kosmetiese fasette van vakkommunikasie beskou te word nie. Indien 'n natuurwetenskaplike wil verseker dat sy/haar boodskap eenduidig gelinterpreteer word, moet ook gestreef word na noukeurigheid in taalgebruik.

\section{Bedanking}

Ons bedank graag verskeie kollegas en vriende vir hul hulp en voorstelle tot die verbetering van hierdie artikel.

\section{BRONNE}

Botha. J.P. \& Van Aardt, J.M.H. (1978). Afrikaans vir die praktyk (McGraw-Hill, Johannesburg).

Carstens, W.A.M. (1994). Norme vir Afrikaans, Derde, hersiene uitgawe (Van Schaik, Pretoria).

Combrink, J. Spies, J. (1986). Sakboek van regie Afrikaans (Tafelberg. Kaapstad).

De Villiers, M., Smuts, J., Eksteen, L.C. Gouws, R.H. (1987). Nasionale Woordeboek. Sewende, hersiene uitgawe (Nasou, Kaapstad).

Taalkommissie van die Suid-Afrikananse Akademie vir Wetenskap en Kuns (1991). Afrikaanse woordelys en spelreels. Agste uitgawe (Tafelberg, Kaapstad). 